\title{
A Utilização de Métodos Qualitativos na Ciência Política e no Marketing Político' ${ }^{1}$
}

\author{
Luciana Veiga \\ Universidade Católica de Petrópolis \\ Laboratório de Pesquisas em Comunicação Política e Opinião Pública, luperj \\ Doutoranda em Ciência Política, luperj \\ Sônia Maria Guedes Gondim \\ Departamento de Psicologia da Universidade Federal da Bahia
}

\begin{abstract}
Resumo
O artigo discorre sobre a utilização da abordagem qualitativa na Ciência Política e no Marketing Político. As discussões apresentadas derivam-se, principalmente, da experiência acadêmica com a pesquisa Ideologia Política, Propaganda Eleitoral e Voto: o efeito persuasivo do Horário Eleitoral na Campanha da Presidência da República, em que foram empregadas as técnicas de entrevista em profundidade e grupos focais.
\end{abstract}

Palavras-chave: métodos qualitativos, marketing político, grupos focais, campanha presidencial de 1998

Abstract

This paper discusses the use of qualitative research technie to the study Political Science and to the Political Marketing. The issues discussed here drawn from the research on Political Ideology, Electoral Propaganda and Votes: the effect of "horário electoral" on the presidency campaign, in which were used depth interviews and focus group technies.

Key words: qualitative methods, political marketing, focus groups, 1998 presidency campaign

\footnotetext{
${ }^{1}$ Agradecemos os comentários e sugestões do Prof. Marcus Figueiredo. Desnecessário dizer que eventuais equívocos são de responsabilidade das autoras.
} 


\section{Introdução}

A Ciência Política tem como objeto de estudo os fenômenos políticos, particularmente as questões relativas ao poder, procurando examinar criteriosamente os fatos, atendo-se não só à descrição como também à explicação destes fenômenos (Bobbio, Matteucci \& Pasquino, 1986). Cada vez mais o interesse desta disciplina se dirige para o entendimento do comportamento das pessoas e dos grupos, como, por exemplo, as formas de participação política, o processo decisório do voto e a utilização das novas tecnologias de comunicação na formação e difusão do pensamento político.

O homem em sua ação política é o alvo da pesquisa em Ciência Política, mas sabe-se que este homem também tem uma dimensão biológica, social, histórica, econômica e psicológica.

Metodologias, quantitativas e qualitativas, no sentido mais amplo, e técnicas de investigação, no sentido mais estrito, concorrem para dar conta desta complexa tarefa, em que se destacam a análise de documentos, a observação direta, a pesquisa participante, os questionários, as entrevistas em profundidade e, mais recentemente, os grupos de discussão.

O marketing político surgiu em 1952 e pode ser definido como um conjunto de técnicas e procedimentos cujo objetivo é avaliar aspectos psicológicos do eleitorado, visando embasar estratégias para aumentar a aceitação do candidato junto à população. Basicamente centra-se: i) na imagem dos candidatos, dos partidos políticos e dos adversários, ii) nos aspectos psicológicos dos eleitores e, por fim, iii) no acompanhamento de todo o processo eleitoral, intervindo de modo ativo conforme os objetivos pretendidos (Figueiredo, 2000).

O quadro atual ainda mostra um distanciamento significativo entre a Ciência Política e o Marketing Político. Ambos parecem estar em posições opostas. De um lado, os adeptos do Marketing Político defendem que a escolha eleitoral cada vez mais se distancia do plano racional e, sendo assim, afirmam que questões acadêmicas sobre Ciência Política são pouco pragmáticas no sentido de permitir uma atuação mais direta no processo político. De outro lado, os acadêmicos acusam os marketeiros de reduzirem o fenômeno político a uma questão estética e psicológica, uma vez que suas preocupações recaem sobre a construção de uma imagem dos candidatos a cargos públicos, que desperta a sensibilidade emocional do eleitor, deixando de lado um aspecto mais importante que é o da ideologia partidária, em que se inclui a discussão de projetos mais amplos para a sociedade e a humanidade.

Este artigo parte da premissa de que a Ciência Política e o Marketing Político não são antagônicos. Pelo contrário, defende que ambos podem contribuir para o aperfeiçoamento mútuo, uma vez que a teoria política traz grande contribuição para a análise das campanhas políticas e, por sua vez, os conceitos da Ciência Política devem estar lastreados por referências empíricas. Desta forma, acredita-se que uma maior 
integração entre Ciência Política e Marketing Político resultará em significativos avanços para o mundo acadêmico e para o mercado.

Adotando esta postura, foi realizada uma pesquisa de cunho acadêmico sobre eleições em 1994, quando procurou-se avaliar o impacto das mensagens eleitorais na formação da opinião dos telespectadores. A pesquisa Propaganda Política e Voto: $O$ Estudo do Efeito da Persuasão do Horário Eleitoral - Estado do Rio de Janeiro - 1994 - $2^{\circ}$ Turno foi desenvolvida a partir de relatórios de discussões em grupos realizados pelo Vox Populi.

Uma pesquisa mais aprofundada foi desenvolvida na eleição presidencial de 1998 sobre o comportamento dos eleitores de camada social mais baixa, valendo-se das técnicas de entrevista em profundidade e de grupos focais. O objetivo foi o de elucidar os recursos que o eleitor utiliza para processar as informações do contexto político e aquelas veiculadas pelo Horário Gratuito de Propaganda Eleitoral. A pesquisa Ideologia Política, Propaganda Eleitoral e Voto: o efeito da persuasão do Horário Eleitoral na campanha para Presidência da República ${ }^{2}-1998$ foi realizada pelo Laboratório de Pesquisas em Comunicação Política e Opinião Pública do IUPERJ (Instituto Universitário de Pesquisa do Rio de Janeiro) e pelo Centro de Pesquisas Sociais da UFJF (Universidade Federal de Juiz de Fora).

As pesquisas foram realizadas a partir de técnicas qualitativas, principalmente, as entrevistas em profundidade e os grupos focais, uma vez que demonstram ser adequadas para a compreensão do comportamento do eleitor, não só no seu processo de formação de opinião e tomada de decisão individual, mas enquanto participante de grupos sociais sujeitos a múltiplas influências na formação e mudança de atitudes políticas.

Este artigo tem como objetivo específico discorrer acerca das técnicas de entrevista em profundidade e dos grupos focais na investigação em Ciência Política e no Marketing Político e, para tal, partiu-se da pesquisa realizada por ocasião da campanha presidencial em 1998.

\footnotetext{
${ }^{2}$ A referida pesquisa foi coordenada pelos professores Raul Magalhães e Luciana Veiga, sob orientação do professor Marcus Figueiredo do IUPERJ. A pesquisa teve apoio financeiro da Fundação de Amparo à Pesquisa do Estado de Minas Gerais ( FAPEMIG). A professora Sônia Gondim coordenou os 20 grupos focais, e o recrutamento dos participantes ficou sob a responsabilidade da Cenário Consultoria e Pesquisa de Juiz de Fora.
} 


\section{A abordagem qualitativa na pesquisa política}

É bastante visível que o desenvolvimento dos meios de comunicação de massa, particularmente o rádio e a televisão, imprimiu um novo ritmo aos processos sociais e políticos. Uma de suas maiores conseqüências foi a de aproximar o candidato à realidade cotidiana de seu eleitorado, minimizando o papel do partido nesta mediação. Uma outra vantagem foi a de garantir a sincronicidade das informações, ou seja, permitir que as pessoas dirijam sua atenção, ao mesmo tempo, para um único assunto, dada a força de sua penetração social (Magalhães, 1993). E, se as pessoas podem ter como centro de suas discussões o mesmo assunto, ficam mais susceptíveis às pressões para a homogeneização de suas opiniões.

Este poderoso processo de 'influenciação', seja por via direta, televisão-eleitor, seja por via indireta, televisão-formador de opinião-eleitor, que ocorre no dia-a-dia das pessoas na época do pleito, pode ser facilmente visualizado nas discussões que surgem nos grupos focais ou nas entrevistas em profundidade. Assim, a investigação qualitativa ganha significativa importância na elucidação dos impactos da propaganda política no comportamento do eleitor, tanto para atender um compromisso de cunho acadêmico, quanto de pesquisa de mercado.

É digno de nota constatar que apesar das pesquisas qualitativas terem aumentado sua importância no planejamento de campanhas políticas, ainda são pouco exploradas pela Ciência Política. Tradicionalmente, os resultados das pesquisas qualitativas, ao contrário das quantitativas, amplamente divulgados nos meios de comunicação, são de acesso restrito à equipe de marketing de cada candidato, o que torna compreensível, em parte, sua pouca utilização nas investigações acadêmicas.

Dentre os objetivos das pesquisas de mercado com abordagem qualitativa destacam-se os seguintes:

i) Conhecer os eleitores, mapeando suas demandas e frustrações;

ii) Compreender sua percepção acerca do quadro político, apontando aspectos positivos e negativos;

iii) Identificar suas expectativas com relação à solução dos problemas sociais;

iv) Avaliar a imagem dos candidatos e as razões para votar ou não nos mesmos e

v) Aferir a avaliação de propostas e programas de governo.

Durante o processo de campanha, a pesquisa qualitativa passa a ter como objetivo a avaliação das estratégias de divulgação por meio da análise do impacto na opinião pública dos programas veiculados pelo Horário Gratuito de Propaganda Eleitoral (HGPE) e isto pode vir a ser útil no esclarecimento de questões relativas ao comportamento do eleitor, de grande interesse acadêmico. 


\section{Entrevistas em profundidade}

A entrevista é uma técnica através da qual o pesquisador se coloca diante do participante para quem faz perguntas com o objetivo de obter informações que contribuam para a investigação. Trata-se de um diálogo assimétrico em que o pesquisador busca coletar dados e o interlocutor se apresenta como fonte de informação. As entrevistas procuram explorar o que as pessoas sabem, crêem, esperam, sentem e desejam.

De acordo com a sociologia fenomenológica (Schultz, 1974), o mundo social é criado e reproduzido pela repetição dos cursos de ação, aprendidos no cotidiano e, sendo assim, para se abordar temas sociais e políticos é preciso fazê-lo a partir do dia-a-dia das pessoas. As experiências diárias vividas e transmitidas pelas pessoas na sociedade compõem o 'estoque de conhecimentos' de que cada um dispõe para interagir com o mundo, interpretá-lo, tomar decisões e ajustar-se a ele.

Desta maneira, as qualidades da pessoa (a imagem que faz de si mesmo, como se comporta em determinadas situações concretas, quais os seus valores e como se relaciona socialmente) e a sua história e suas experiências de vida (a família, a escola, a profissão etc) devem ser abordadas nas entrevistas em que se investigam atitudes e a decisão política. Dito de outro modo, as questões referentes ao cotidiano dos participantes são capazes de trazer importantes contribuições para a entendimento da percepção que possuem sobre política.

As entrevistas em profundidade podem ser realizadas com formadores de opinião ou com os cidadãos comuns. No primeiro caso, intelectuais, jornalistas, professores, líderes de classe e empresários são entrevistados com o objetivo de mapear o quadro da disputa eleitoral. No segundo caso, os pesquisados são eleitores comuns e o objetivo é o de identificar as estruturas cognitivas que as pessoas possuem e utilizam na decisão do voto.

A entrevista em profundidade tem um caráter subjetivo, o que torna necessário que toda interpretação deva levar em consideração a perspectiva da pessoa analisada. Sua vida e seu mundo só podem ser entendidos a partir 'de seus olhos'. É neste aspecto que as entrevistas em profundidade apresentam-se como mais pertinentes se se pretende aproximar da realidade social e política e das representações que o eleitor constrói dela.

É preciso, então, tomar cuidado com o nível de estruturação a ser adotado. As entrevistas podem apresentar diferentes níveis. Há aquelas mais estruturadas que seguem um rígido roteiro e restringem as possibilidades de aprofundamento e de abordagens variadas do tema, não pertinentes às entrevistas em profundidade, e as semiestruturadas que adotam um roteiro flexível como norteador, o que favorece o diálogo com o entrevistado, aprofundando aspectos importantes para a compreensão de seu pensamento e sentimentos sobre o assunto em pauta.

Conforme assinala Lane (1962), uma das vantagens das entrevistas em profundidade é que elas são discursivas, permitindo a cada entrevistado demonstrar sua 
linha de argumentação de modo que o entrevistador possa inferir as associações que faz em seus pensamentos oferecendo, inclusive, oportunidades para extensivas sondagens de opiniões, atitudes e valores dos participantes.

\subsection{Procedimentos práticos para utilização de entrevistas em profundidade}

Um dos objetivos de pesquisas qualitativas sobre comportamento político, em que se inclui o interesse em analisar o impacto persuasivo da propaganda eleitoral na formação de opinião, e que escolhem a entrevista em profundidade como técnica de coleta de dados, é o de conhecer as estruturas cognitivas utilizadas pelos cidadãos ao pensar sobre questões políticas e interpretar informações apresentadas na propaganda eleitoral, particularmente aqueles pertencentes às classes baixas, que constituem a maior parte do eleitorado brasileiro.

Partindo da constatação que a formação de opinião é um processo (Kruger, 1986; Morales, 1997; Myers, 1999; Rodrigues, Assmar \& Jablonski, 2000), devem ser realizadas, em média, quatro ou cinco entrevistas com cada um dos participantes, ao longo de cinco a seis meses, recrutados com base nos seguintes critérios: nível de renda, nível educacional, idade, sexo e ocupação. Como a maior parte do eleitorado é proveniente de classes baixas sugere-se maior atenção junto àquelas pessoas cujo nível de renda esteja entre dois a cinco salários mínimos e não possuam mais que oito anos de escolaridade.

As entrevistas, com duração de uma hora aproximadamente, devem ser desenvolvidas com base num roteiro semi-estruturado, que permite maior aprofundamento da temática e da experiência pessoal do entrevistado. Os encontros podem ser realizados na residência do próprio entrevistado ou num laboratório, conforme a receptividade de cada participante.

A forma de recrutamento mais comum em pesquisas qualitativas é por critério de conveniência, como, por exemplo, a técnica da bola de neve, em que os participantes sugerem outros participantes para serem entrevistados, sendo indicada também, quando se pretende estudar um grupo de acesso restrito cujos componentes não aparecem enumerados em uma lista para uma escolha aleatória (Weiss,1994).

As entrevistas devem ser gravadas em fitas cassetes, primeiro porque permitem a reprodução exata dos depoimentos e segundo, porque libera o entrevistador das anotações, centrando sua atenção na fala do entrevistado.

Com fins de análise interpretativa, as entrevistas devem ser transcritas, codificadas e categorizadas. Conforme a orientação teórica dos pesquisadores podem ser empregadas técnicas de análise de conteúdo (Bardin, 1977), cuja ênfase recai no conteúdo manifesto do discurso e nos argumentos apresentados, e de análise de discurso (Maingueneau, 1997), se o foco recair sobre o nível ideológico subentendido no discurso. 


\subsection{Alguns exemplos da pesquisa eleitoral presidencial de 1998, realizada com entrevistas em profundidade.}

Ao sentar-se junto a um entrevistado, ao analisar seu depoimento, o entrevistador deve procurar entender por que o seu interlocutor pensa como pensa e age como age, pois ele tem sempre boas razões para fazê-lo. É isso que se busca a partir da análise do discurso do cotidiano, presente nas entrevistas e nos grupos de discussão.

As interpretações que porventura são feitas com base nas transcrições permitem lançar luz sobre aparentes inconsistências no pensamento dos eleitores. Uma razão parece justificar algumas inconsistências - as limitações cognitivas dos próprios participantes - que pode ser ilustrada por depoimentos de um rapaz que em sua primeira entrevista ao responder à questão sobre o que mais o havia irritado ultimamente na imprensa, discorreu longamente sobre o processo de 'leilão' da Vale do Rio Doce. Nas duas entrevistas seguintes, ao se deparar com a pergunta sobre sua postura diante da privatização de estatais, disse que não sabia falar a respeito. Isto parecia estranho, uma vez que já o havia feito em outra oportunidade. O que parecia estar acontecendo é que o rapaz não sabia que o termo privatização estava relacionado aos termos venda e leilão. Com tais limitações, o entrevistador tem que ser hábil, sob pena de perder pontos importantes que em muito esclarecem o caso estudado. Uma entrevista que abordasse esse eleitor apenas em um único momento, não levando em conta o conhecimento ao longo de várias entrevistas, poderia levar a uma conclusão equivocada acerca da sua capacidade de compreensão da problemática em questão, uma vez que não poder-se-ia contextualizar a resposta e dissolver a aparente contradição.

Cabe acrescentar que os eleitores de classe baixa parecem não só apresentar um quadro limitado de referências para decidir seu voto, como também não demonstram possuir conceitos específicos para tratar de temas que escapem ao seu cotidiano, partindo dele, inclusive, para lidar com assuntos políticos. Em função disto, centralizar a entrevista nos aspectos da vida cotidiana é ainda uma estratégia que visa facilitar a conversação sobre questões mais complexas e especializadas.

Na pesquisa de 1998, cujos participantes foram recrutados entre as classes $\mathrm{C} \mathrm{e}$ $D$, foi possível perceber que, embora muitos deles não fossem capazes de entender regras gerais e abstratas sobre o mundo da política, havia sempre a possibilidade de interpelá-los sobre a solução que dariam para situações concretas. Em outras palavras, para investigar o nível ideológico era necessário ancorá-los no cotidiano, pois era justamente a partir dele que emitiam suas opiniões sobre política. Ao falarem, por exemplo, sobre os motivos do desemprego, um dos grandes temas da campanha, na época, os entrevistados utilizaram-se de suas experiências cotidianas. $O$ exemplo a seguir é uma ilustração disto. 
"Esta onda de desemprego, eu não sei o que é que está acontecendo porque eu politicamente assim eu não sei nada. Eu trabalho na rua, externo, é área de vendas, eu não estou conseguindo vender nada. Você chega para vender alguma coisa e só escuta: -'Ah, eu estou fechando'. Eu penso desta maneira , que eu escuto as pessoas dizerem: -'Eu tinha tantos funcionários e hoje estou com tantos, porque não tenho como pagar. Eu não agüento mais pagar impostos.' E também tem essa coisa do computador, a tecnologia vem avançando demais quer dizer vai ocupando o lugar do homem."

Enfim, para se compreender como o eleitor comum interpreta os acontecimentos sociais e age politicamente é preciso acompanhar o curso de seu pensamento, sua forma de representação e seu linguajar e, neste caso, a abordagem qualitativa e a entrevista em profundidade numa perspectiva longitudinal oferecem condições mais favoráveis para alcançar este objetivo.

\section{Grupos de discussão ou grupos focais}

O grupo focal ou grupo de discussão, como técnica de pesquisa qualitativa, apresenta-se como uma possibilidade para compreender a construção das percepções, atitudes e representações sociais de grupos humanos acerca de um tema específico. Apoiado nas entrevistas grupais (Bogardus, 1926; Merton, 1990), tal técnica pode ser usada em três perspectivas: i) como principal fonte de dados (self-contained), ii) como fonte suplementar de dados, tanto para subsidiar programas de intervenção, quanto elaborar instrumentos de pesquisa experimental e quantitativa e iii) como fonte complementar de dados, ao ser associado às técnicas de entrevistas em profundidade e de observação participante (Morgan, 1988).

Inseridos numa abordagem metacientífica mais ampla, ou seja, a da compreensão e da hermenêutica, em que se procura aproximar o investigador do contexto psicológico, social e cultural dos participantes da pesquisa, visando interpretar melhor suas ações (Bion, 1961; Guess, 1988; Holzkamp, 1977; Pichón-Riviére, 1975; Schultz, 1978), o objetivo final dos grupos focais, principalmente os auto-referentes (tradução livre de selfcontained), reside na emancipação a ser alcançada através da conscientização dos participantes da pesquisa, capacitando-os a efetuar mudanças no plano social. Em resumo, os grupos focais servem a dois propósitos: criar condições para que os participantes da pesquisa possam exercer um papel mais ativo nos processos de produção do conhecimento e, ao mesmo tempo, oferecer-lhes oportunidade de conscientização de sua situação atual, dando-lhes maior poder de transformação ${ }^{3}$.

\footnotetext{
${ }^{3}$ Mais amplamente conhecido fora da área acadêmica, principalmente no setor publicitário (Edmunds, 1999), o grupo focal tem sido usado recentemente em pesquisas de saúde pública, em virtude da preocupação com a educação para a saúde, proposta compatível com a atuação pedagógica-educativa desta técnica de investigação e intervenção qualitativa (CarliniCotrim, 1996 ).
} 
A partir dos últimos anos da década de 80 , vimos assistindo ao crescimento do marketing político em que se inclui a difusão de abordagens metodológicas qualitativas, especificamente através da técnica dos grupos focais, servindo de complementação às abordagens quantitativas já usadas em pesquisas de opinião pública (Figueiredo, 2000; Lunt \& Livingstone, 1996; Magalhães \& Veiga, 2000).

A premissa básica dos grupos de discussão é a de que as pessoas formam as suas opiniões e percepções nos processos interativos em que se engajam, sendo mutuamente influenciadas pelo jogo de forças que vai se constituindo nas relações interpessoais, intra e intergrupais. Constitui, a rigor, um nível de análise distinto do das entrevistas individuais em profundidade. Neste último caso, privilegia-se a compreensão do contexto da pessoa.

Os grupos focais (ou de discussão) na pesquisa política podem ser explorados de modo a alcançar os objetivos: explorar as estruturas cognitivas identificadas em entrevistas individuais, previamente realizadas, comparando-as com as manifestações grupais, e servir como fonte principal de coleta de dados, quando a ênfase passa a ser nos processos de 'influenciação' social que estão na base da formação de opiniões, atitudes e valores.

\subsection{Procedimentos práticos para a utilização dos grupos focais}

Os recursos técnicos e humanos necessários variam conforme as modalidades de grupos focais ou de discussão que se pretende adotar. Os grupos podem ser desenvolvidos através do uso de computadores e da internet, de telefones e do contato pessoal direto, neste último caso é necessário uma sala especial. As considerações feitas neste artigo estão alicerçadas na experiência com grupos focais de contato pessoal direto. Sendo assim, os recursos técnicos e humanos para sua realização encontram-se especificados a seguir:

i) sala especial com espelho unidirecional, com uma mesa retangular ou oval que permita dispor aproximadamente 10 cadeiras;

ii) microfones para gravação;

iii) câmera de vídeo com tripé, a serem alocados atrás do espelho unidirecional;

iv) sala anexa à especial com entrada independente e equipada com aparelho de

TV que permita à equipe de pesquisadores e assistentes acompanhar a gravação do grupo;

v) um profissional habilitado para coordenar os grupos.

Caso o interesse da pesquisa resida em acompanhar o programa eleitoral gratuito, e a discussão em grupo seja realizada subseqüentemente, deve-se providenciar um aparelho de televisão para a sala especial.

$\mathrm{Na}$ utilização de grupos de discussão é preciso determinar o número total de grupos necessários para explorar a temática em questão que pode variar conforme sua 
complexidade. Na pesquisa realizada em 1998 (Magalhães \& Veiga, 2000) , por exemplo, foram compostos 20 grupos de discussão, um para cada dia de exibição do Programa Eleitoral Gratuito que reunia os presidenciáveis, exibido pela televisão no período de 18 de agosto a $1^{\circ}$ de outubro, sempre as terças, quintas e sábados, no horário de 20 às 20 hs e 25 minutos. O critério mais seguro, contudo, é o da previsibilidade de respostas, ou seja, acredita-se que a estrutura de significados tenha sido apreendida quando os grupos não apresentam novidades em termos de conteúdo e argumentos e se tornam repetitivos.

O número de participantes em grupos focais pode variar de oito a dez. A duração de cada grupo de discussão oscila de uma hora e meia a duas horas, conforme o número de participantes e a polêmica da temática.

A dinâmica do Funcionamento do grupo focal/grupo de discussão, particularmente de acompanhamento de campanhas eleitorais televisivas, deve ser planejada para ter três etapas, assim especificadas:

$1^{a}$ Etapa

$1^{\circ}$ passo - Apresentação informal dos participantes, em que se procura conhecer os participantes - como se chamam, profissão, onde moram, o que gostam de fazer para se divertir - e o seu nível de envolvimento com a política, tentando explorar como avaliam a situação no momento.

Além disso, informações gerais sobre o processo de pesquisa - apresentação da metodologia qualitativa, da pesquisa, do coordenador ou moderador do grupo - devem ser transmitidas aos participantes, ressaltando, inclusive, a necessidade da gravação em vídeo e/ou em fitas cassetes da sessão, assim como a garantia de anonimato.

$2^{\circ}$ passo - Aplicação de um questionário simples sobre a intenção de voto. Podese utilizar o recurso de discos com os respectivos nomes dos principais candidatos para que cada participante assinale com um $\mathrm{X}$ o nome de seu candidato;

$3^{\circ}$ passo - Introdução da temática principal, conforme roteiro semi-estruturado, que pode ser feita através da técnica dos grupos nominais (Schermerhorn, Hunt \& Osborn, 1999), que consiste na formulação oral de uma pergunta, pelo coordenador do grupo, a ser brevemente respondida individualmente e por escrito, por cada um dos participantes. O objetivo desta técnica, neste caso, é o de documentar algumas opiniões pessoais sem a influência do grupo e preparar psicologicamente os participantes para a discussão. No caso de se querer avaliar o impacto do programa eleitoral gratuito, a técnica dos grupos nominais pode ser aplicada após a audiência ao referido programa, cuja ênfase deve recair sobre os aspectos que chamaram a atenção nos programas eleitorais daquele dia e sobre a maneira como os participantes avaliaram os candidatos e seus partidos;

$4^{\circ}$ passo - Assistir ao programa eleitoral televisivo em tempo real.

$5^{\circ}$ passo - Discutir os programas exibidos (o que chamou mais a atenção, o que gostou, o que não gostou, sinceridade dos candidatos, recursos técnicos, tempo disponível, temas abordados, presença de artistas, etc.) e, com o objetivo de avaliar a 
dinâmica grupal pode-se, após cerca de 1 hora de discussão, distribuir um questionário em que se solicita que os participantes avaliem comparativamente, tanto os candidatos, quanto os seus programas em vários tópicos: saúde, educação, desemprego, políticas sociais, etc. No final do questionário solicita-se que o participante esboce novamente sua intenção de voto, escrevendo por extenso o nome do candidato em quem irá votar e

$6^{\circ}$ passo - Para avaliar a mudança ou a manutenção de intenção de voto (resposta do disco $\mathrm{X}$ última pergunta do questionário) deve-se solicitar a cada um dos participantes que se manifeste oralmente.

\subsection{O papel do coordenador/moderador de grupos focais}

O moderador é um dos principais responsáveis pelo sucesso dos grupos focais. Apesar de contar com o apoio de um grupo de colaboradores, dentre os quais destacamse os recrutadores, cabe a ele a responsabilidade de preencher os quatro requisitos para o sucesso dos grupos focais, segundo Merton, Fiske e Kendall (1990), a saber: i) cobrir o máximo possível o tópico, ii) conseguir que o grupo ofereça informações mais específicas; iii) promover interações que permitam explorar, em profundidade, os sentimentos dos participantes e iv) levar em conta o contexto pessoal que os participantes usam para construir suas respostas.

Em outras palavras, é preciso que o moderador tenha habilidade técnica para lidar com grupos e apóie suas intervenções numa teoria que descreva o funcionamento de grupos.

A habilidade técnica expressar-se-á pela competência em:

i) intervir o mínimo possível no funcionamento do grupo;

ii) incentivar o envolvimento de todos, principalmente nos momentos em que houver polarização que ameace a manifestação de outros participantes;

iii) identificar e explorar aquelas opiniões promissoras para a compreensão das razões e significados da escolha e/ou conduta dos participantes;

iv) ter agilidade e flexibilidade para introduzir elementos novos, sob a forma de perguntas, se o grupo se tornar redundante e repetitivo.

A fundamentação teórica do coordenador ajudará não só na seleção dos aspectos a serem observados, como também na análise e interpretação dos resultados. Um coordenador, cuja base teórica se apóie na Psicologia dos Processos Grupais, poderá enfocar, por exemplo:

i) direção da comunicação intragrupal: a quem se dirige;

ii) tipos de apelo persuasivo - afetivo, racional ou físico;

iii) tipos de confrontos estabelecidos;

iv) alianças intragrupais;

v) disposição espacial entre oponentes e aliados. 


\section{3. Análise e interpretação dos resultados}

A análise e interpretação dos resultados de um grupo de discussão devem partir da transcrição de todas as fitas de vídeo e/ou fitas cassetes, e levar em conta fundamentalmente as perguntas formuladas no início da pesquisa. Cabe destacar que as respostas que esta técnica pode vir a dar são um pouco diferentes daquelas obtidas em entrevistas individuais em profundidade.

Os seguintes aspectos devem ser avaliados:

i) amplitude da compreensão que se pretende alcançar, que pode ser obtida em duas dimensões. A do plano horizontal, que surge a partir dos comentários e argumentos esboçados durante a discussão e da verbalização de opiniões divergentes e convergentes; e a do plano vertical, fruto da comparação entre todos os grupos de discussão de modo a identificar persistentes manifestações verbais e não verbais afetivas e argumentativas;

ii) o plano de análise grupal e interindividual, mais do que individual - que é o caso das entrevistas em profundidade;

iii) descrição do processo grupal em que as opiniões são manifestadas, em que pese a influência do líder sobre os outros membros do grupo; forças opositoras; compartilhamento de significados positivos e/ou negativos atinentes a partidos políticos e candidatos.

\subsection{Alguns exemplos da pesquisa eleitoral presidencial de 1998, realizada com grupos de discussão}

Um dos pontos importantes a se ratificar é o de que as pessoas avaliam questões políticas com base no seu cotidiano, o que fica bastante evidente nos grupos focais. As discussões partem do que acontece em casa, no bairro, na cidade e no país. Há que assinalar, contudo, que em alguns momentos essas mesmas pessoas revelam certa incompreensão acerca de questões econômicas e políticas mais complexas.

Três exemplos podem ajudar a ilustrar. O primeiro se refere à percepção no cotidiano de que há polaridades no mundo: 'nós', os pobres, excluídos e injustiçados e 'eles', os ricos, inseridos e injustos. Em um grupo de discussão, encorajado a opinar sobre a política econômica do governo Fernando Henrique Cardoso (FHC), um dos participantes disse:

"Então você vê, você vai comprar um arroz que custa este valor, nem canjiquinha você compra por este preço. Eu queria que eles viessem aqui em baixo e fossem viver com um salário mínimo."

O segundo exemplo ilustra a avaliação do governo, feita pelo eleitor, com base na experiência concreta, o que foi criticado por outro participante. No último grupo de discussão, um eleitor do Lula perguntou para uma eleitora de $\mathrm{FHC}$ o que havia melhorado 
na sua vida com o governo de FHC, mas adiantou-se a ela e acrescentou: -"Não me diga que você comprou televisão e geladeira na Brasimac em não sei quantas prestações e que conseguiu casar!' Seu comentário foi acompanhado de risos pelos outros membros do grupo e comentários paralelos, numa referência nítida à resposta típica do eleitor de FHC, qual seja, a de que houve controle da inflação através do Plano Real, o que permitiu a aquisição de bens pela classe pobre.

O terceiro exemplo trata da incompreensão acerca de questões mais complexas da política. Num grupo de discussão, dois eleitores do Lula reclamavam a uma eleitora do $\mathrm{FHC}$ que o atual presidente e candidato viajava muito para o estrangeiro e não acompanhava o que estava acontecendo no Brasil. A eleitora do FHC dizia que isto era muito bom para o Brasil, porque ele representava o país lá fora. No calor da discussão, um dos eleitores de Lula disse :

"Você só vê as coisas saindo daqui e não vê nada chegando de lá pra cá"

A eleitora de $\mathrm{FHC}$ retrucou:

"Mas isto é muito bom! As coisas saindo mais do que entrando!"

A resposta subentendia a compreensão do conceito de balança comercial positiva a que ela estava se referindo, ou seja, o de que exportar é mais importante do que importar, que não parecia muito claro para aquele eleitor do Lula, que fazia referência apenas às freqüentes viagens de FHC ao exterior. A discussão parecia estar apoiada em planos de entendimento diversos. Deste modo, o debate se desenrolou e nenhum participante se preocupou em esclarecer o que estava acontecendo. Isto retrata, em parte, a realidade cotidiana das interações humanas em que as opiniões são formadas, de modo que boa parte delas passa a ser adotada acriticamente.

Nos grupos focais também ficou bastante evidente o jogo de 'influenciação' social. Naqueles em que havia dois ou três fortes defensores de seus pontos de vistas, a tentativa de reorientação dos valores e crenças dos indecisos iniciava-se rapidamente. Ao final da sessão alguns diziam que mudaram sua intenção de voto depois do grupo, pois ali puderam esclarecer algumas de suas dúvidas. Quando havia uma divisão mais eqüitativa de definidos e ao mesmo tempo oponentes o eixo da discussão recaía sobre a argumentação a favor do seu candidato e do partido e de críticas em relação aos adversários. Ficou claro que o poder de 'influenciação' é limitado. Quando a pessoa já tem uma opinião formada sua preocupação centra-se na sustentação de seus pontos de vista, ao passo que o indeciso fica vulnerável e busca encontrar algum apoio social.

Enfim, ainda que o grupo focal não represente realisticamente a conversa do botequim, da fila de ônibus e da roda de amigos, ele pode lançar luz sobre o entendimento do processo social de formação das opiniões dos eleitores. 


\section{Conclusão}

Com este artigo tentou-se dar uma pequena contribuição quanto às possibilidades de utilização das entrevistas em profundidade e grupos focais na investigação de questões políticas. Tal iniciativa encontra justificativa, principalmente, na ausência de bibliografia a respeito do assunto no Brasil.

As pesquisas de opinião pública estão apoiadas fortemente numa abordagem quantitativa e a utilização de metodologias qualitativas pode ser considerada como uma alternativa ainda pouco explorada. Cabe assinalar contudo, o crescimento de sua prática nas últimas eleições, particularmente na elaboração das estratégias de marketing político.

A principal vantagem da abordagem qualitativa é que ela se apresenta como um recurso que permite compreender o contexto pessoal, no caso da técnica de entrevista em profundidade, e grupal, em se tratando dos grupos focais, a partir dos quais são construídas as opiniões e a visão de mundo dos participantes que avaliam os candidatos, os partidos políticos e decidem sobre o seu voto.

Sobre o caso particular da pesquisa utilizada como exemplo, acredita-se que a conjugação das entrevistas em profundidade com os grupos de discussão ampliou as possibilidades de análise do pensamento dos eleitores, revelando em cada tipo de abordagem facetas extremamente ricas e muitas vezes surpreendentes dos horizontes cognitivos dos cidadãos.

\section{BIBLIOGRAFIA}

BARBOZA FILHO, Rubem. \& MAGALHÃES, Raul Francisco. (1997) As eleições municipais de 1996: a tese da municipalização e a força nacional dos partidos. Comunicação e Política. Vol. IV (1): 38-49, (janeiro-abril).

BARDIN, Lawrence. (1977) Análise de conteúdo. Tradução de Luis Antero Reto e Augusto Pinheiro, Lisboa, Edições 70.

BION, W. (1961) Experiences in group. Londres, Tavistock Institute.

BOBBIO, Norberto; MATTEUCCI, N. \& PASQUINO, G. (1986) Dicionário de política. Tradução: Carmen C. Varrialle, Gaetano Lo Mônaco, João Ferreira, Luís Guerreiro Pinto Cacais e Renzo Dini, Brasília, Editora da Universidade de Brasília.

BOGARDUS, E. S. (1926) The group interview, Journal of Applied Sociology, 10: 372-382.

CARLINI-COTRIM, Beatriz. (1996) Potencialidades da técnica qualitativa grupo focal em investigações sobre abuso de substâncias, Revista Saúde Pública, 30 (3): 285-93.

EDMUNDS, Holly. (1999) The focus group: Research handbook. Chicago, NTC Business Book/Amercian Marketing Association. 
FIGUEIREDO, Rubens. (2000) O marketing político: entre a ciência e a razão. In: FIGUEIREDO, Rubens (org.) Marketing político e persuasão eleitoral. São Paulo, Fundação Konrad Adenauer, p.11- 41.

GUESS, Raymond. (1988) Teorica crítica: Habermas e a escola de Frankfurt. Tradução: Bento Itamar Borges. São Paulo, Papirus.

HOLZKAMP, K. (1977) Pressupostos antropológicos ocultos da psicologia geral. In: GADAMER, Howard G. \& VOGLER, P. (orgs.) Nova antropologia. Coordenador da edição brasileira: Egon Schaden. São Paulo, EPU, Ed. Universidade de São Paulo, vol. 5:169- 200.

KRÜGER, Helmuth. (1986) Introdução a psicologia social. São Paulo, EPU.

MAGALHÃES, Raul Francisco. (1993) A ciência política e o marketing eleitoral: algumas elaborações teórica. Comunicação \& Política. Vol 1 (3):127-38.

MAGALHÃES, Raul Francisco e VEIGA, Luciana Fernandes. (2000) Manipulações cognitivas da político: o eleitor comum diante da campanha presidencial de 1998. In: FIGUEIREDO, Rubens (org.) Marketing político e persuasão eleitoral. São Paulo, Fundação Konrad Adenauer, p.205 231.

MAINGUENEAU, Dominique. (1997) Os termos chaves da análise do discurso. Lisboa, Gradiva.

MERTON, Robert King, FISKE, Marjorie \& KENDALL, Patricia L. (1990) The focused interview: a manual of problems and procedures. New York, Free Press.

MORALES, Jose Francisco. (org.) (1997) Psicología social. Madrid, McGraw-Hill.

MORGAN, David. (1988) Focus group as qualitative research. Newbury Park, Sage Publication.

MYERS, David G. (1999) Social psychology. New York, McGraw-Hill College.

PICHÓN-RIVIERE, Enrique. (1975) El processo grupal: Da psicanálise à psicologia social. Buenos Aires, Ediciones Nueva Vision.

RODRIGUES, Aroldo; ASSMAR, Eveline Maria Leal \& JABLONSKI, Bernardo. (2000) Psicologia social. Petrópolis, Vozes.

SCHULTZ, Alfred. (1974) El problema de la realidad social. Buenos Aires, Amorrortu.

SCHULTZ, William. (1978) Psicoterapia pelo encontro. São Paulo, Atlas.

SCHERMERHORN, John R. ; HUNT, James G. \& OSBORN, Richard N. (1999) Fundamentos de comportamento organizacional. Tradução: Sara Rivka Gedanke. Porto Alegre, Bookman.

WEISS, Robert S. (1994) Learning from stranger: the art and method of qualitative interview studies. New York, The Free Press. 